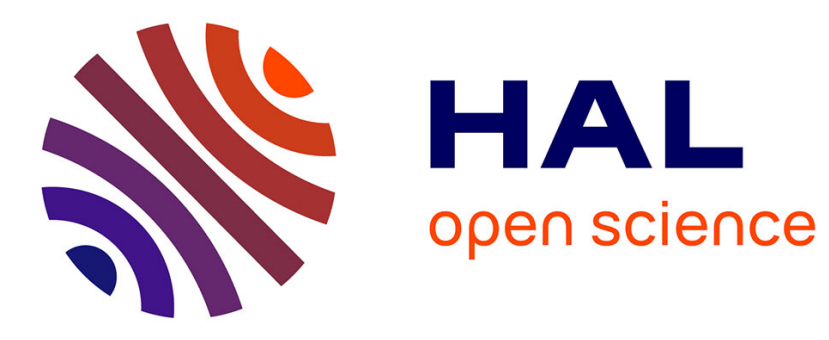

\title{
Singing voice research at the Speech and Cognition Department, GIPSA-lab, Grenoble, France
}

\author{
Nathalie Henrich Bernardoni, Christophe Savariaux
}

\section{To cite this version:}

Nathalie Henrich Bernardoni, Christophe Savariaux. Singing voice research at the Speech and Cognition Department, GIPSA-lab, Grenoble, France. Psychomusicology: Music, Mind and Brain, 2012, 21 (1 \& 2), pp.177-182. 10.5084/pmmb2010/21/xxx . hal-00680693

\section{HAL Id: hal-00680693 https://hal.science/hal-00680693}

Submitted on 19 Mar 2013

HAL is a multi-disciplinary open access archive for the deposit and dissemination of scientific research documents, whether they are published or not. The documents may come from teaching and research institutions in France or abroad, or from public or private research centers.
L'archive ouverte pluridisciplinaire HAL, est destinée au dépôt et à la diffusion de documents scientifiques de niveau recherche, publiés ou non, émanant des établissements d'enseignement et de recherche français ou étrangers, des laboratoires publics ou privés. 


\title{
Singing voice research at the Speech and Cognition Department, GIPSA-lab, Grenoble, France
}

\author{
NATHALIE HENRICH $\mathcal{E}$ CHRISTOPHE SAVARIAUX
}

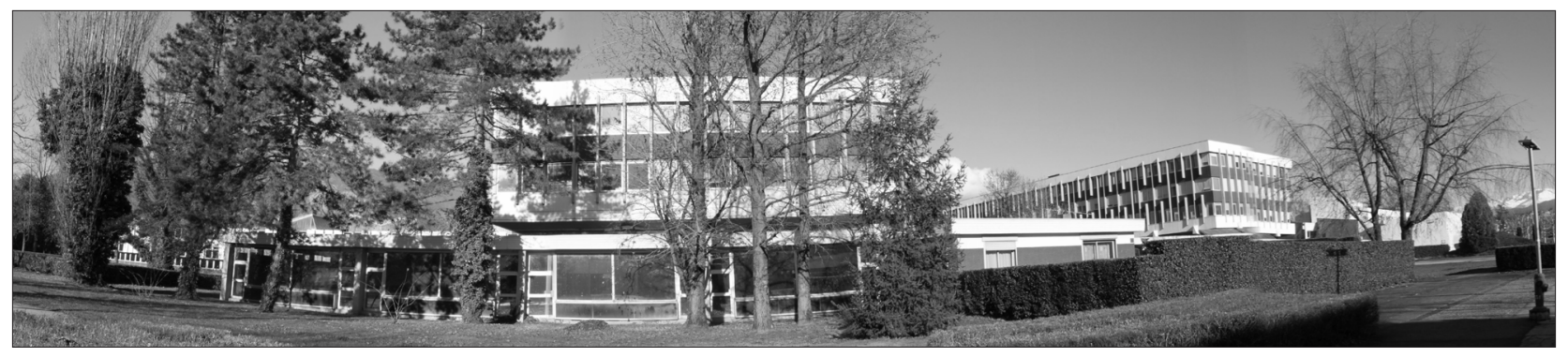

Figure I. GIPSA-lab, a multidisciplinary research laboratory on signals and systems in the French Alps.

DESGRIPTION OF THE RESEARCH

\section{A B O R A T O R Y}

\section{GIPSA-lab: Grenoble Images Speech Signal Automatism}

Located at Grenoble in the heart of the French Alps, GIPSA-lab is a multidisciplinary laboratory where both theoretical and applied scientific research is conducted on signals and systems, be they physical, biological, cognitive or industrial. GIPSA-lab is a joint research unit (UMR 5216) of the French National Center for Scientific Research

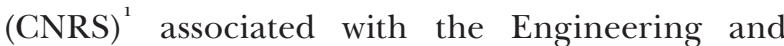
Systems Sciences Institute, of Grenoble Institute of Technologies, of Grenoble University of Sciences, Technology and Health (University Joseph Fourier) and of the Human Sciences University (University Stendhal). It also has partnerships with the French National Institute for Research in Computer Science and Control (INRIA), with Grenoble's Science of the Universe Observatory (OSUG), and with the University of Social Sciences (University Pierre Mendès-France). Its 330-person staff includes around 140 permanent researchers, 120 PhD students, 30 post-PhD students and visiting researchers (per year), 40 people in administrative and technical services (secretariat, finance, communications, documentation, computing, logistics and experimental platforms). GIPSA-lab is composed of three Departments (Speech and Cognition, Image and Signal, Automatism) and 12 research teams, several of which are pertinent to singing. The singing-voice research is conducted in the Speech and Cognition Department.

\section{Speech and Cognition Department (DPC)}

The Speech and Cognition Department has developed a multi-disciplinary field of expertise on human communication, ranging from physics, signal processing to phonetics and language sciences, integrative neurosciences and cognitive psychology. The research studies conducted in the Department aim at increasing scientific knowledge on language, voice and speech communication, at studying and modelling voice and speech signals, together with the physiological and cognitive systems which process them and the linguistic systems which organize them, and at creating virtual conversational agents able to communicate with humans.

Nathalie Henrich, Department of Human and Social Sciences, GIPSA-Lab, CNRS; Christophe Savariaux, Speech and Cognition Department, GIPSA-Lab, CNRS \& Grenoble University.

Address for correspondence: Nathalie Henrich, DPC GIPSAlab, 961 rue de la Houille Blanche, BP 46, F - 38402 GRENOBLE Cedex. E-mail: Nathalie.Henrich@gipsa-lab.grenoble-inp.fr Web link to GIPSA-lab: http://www.gipsa-lab.fr 

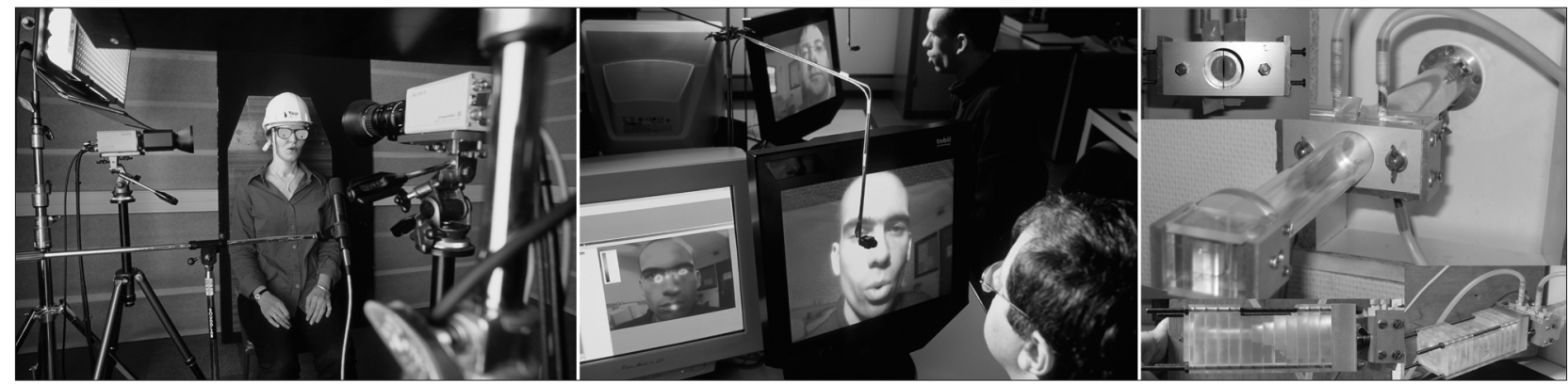

Figure 2: Experimental platforms available at the Speech and Cognition Department of GIPSA-lab. Left panel: Stendhal experimental unit. Middle panel: MICAL unit. Right panel: Aeroacoustic unit. (Photo credit: ๑ CNRS Phototèque / PERRIN Emmanuel)

\section{EXPERIMENTAL PLATFORMS}

Several experimental platforms have been developed at the Speech and Cognition Department of GIPSA-lab to study voice and speech, communication behaviors in the case of human-human or computer-human interaction, and to evaluate physical models of human voice production.

\section{Experimental Unit (Stendhal) to measure speech and singing on human}

The Stendhal experimental unit is dedicated to the characterization of phonatory and articulatory behaviours, and to their audio and visual consequences (if any). The available devices include:

- an electromagnetic articulograph (EMA), which tracks articulatory movements by the use of tiny electromagnetic coils attached to a subject's tongue, lips, or palate in the mid-sagittal plane

- a DPS system for simultaneous capture of three video streams from three high-quality video camera

- a dual-channel electroglottograph (EGG), which measures the vocal-folds contact area

- a computer-aided voice evaluation device (EVA), which allows simultaneous acquisition of electroglottographic signals and acousticalaerodynamical voice parameters, such as the radiated acoustical pressure at the lips, the oral and nasal airflow, and the aerodynamical intraoral pressure (see Figure 3, left panel)

- a device for measuring vocal-tract resonance frequencies during speech or singing (RESONANCE), by injecting the vocal-tract at the lips with a calibrated acoustical-flow source (see Figure 3, right panel)

- a portable ultrasound machine (Terason) to examine tongue shape and movements in phonation
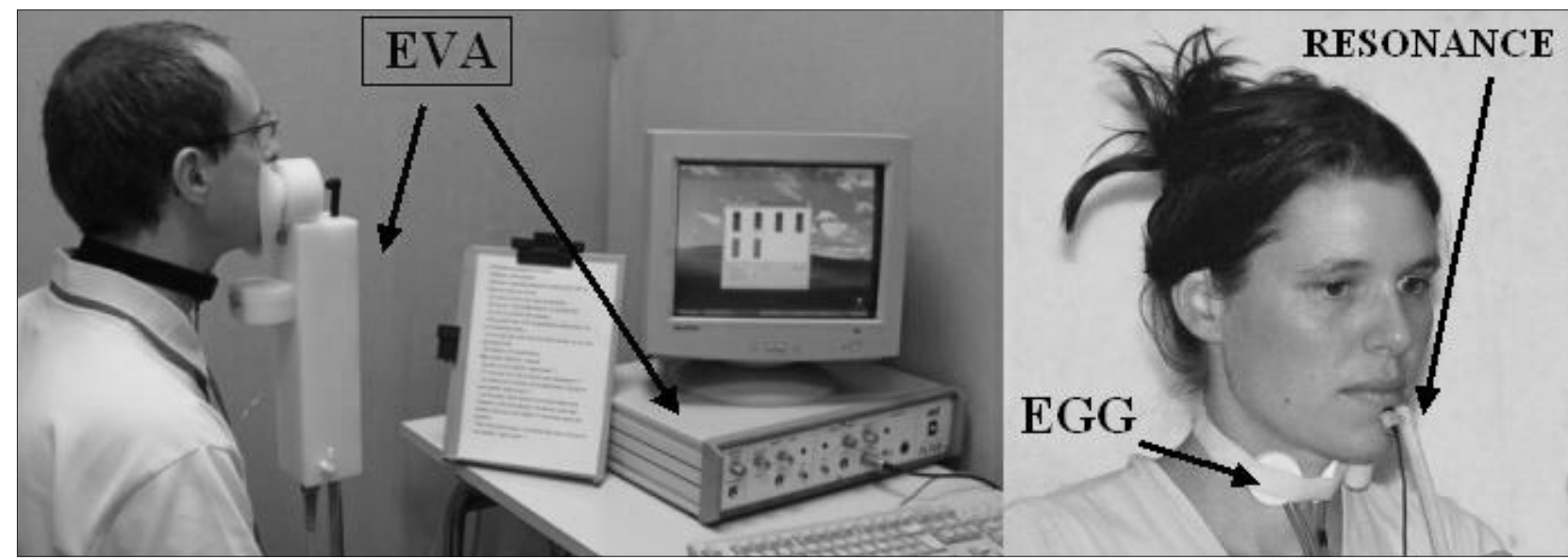

Figure 3: Left picture illustrates the EVA set-up. Right picture illustrates the RESONANCE and EGG devices. 
The measurements are done inside one of the two soundproof and anechoic chambers available at the Department. A portable ultrasound system will soon complete the avalaible devices for measuring real-time articulatory movements.

\section{MICAL unit for face-to-face interaction ${ }^{2}$}

The MICAL unit has been set up to study face-to-face speech communication between two humans, or between a human and an animated conversational agent. It allows recording and characterisation of the shared signals: speech, eye gaze, gestures, posture, and facial expressions. The available devices include several eye trackers, a motion-capture system and an audio-video recording system for face-to-face communication.

\section{AEROACOUSTIC unit for in-vitro measurement of physical phenomena related to voice production}

The experimental set-ups developed in this unit are designed to reproduce, control and measure aerodynamical and/or acoustical phenomena occuring during human voice production, so as to evaluate theoretical physical models. The lower and upper airways are made of simplified replicas, on which acoustical pressure-field distribution and volume-flow rate are measured, in addition to flow visualisation. The vocal-folds vibratory behaviour is reproduced by means of a self-oscillating replica composed of latex tubes (the 'folds') filled with water under pressure. Static or motor-controlled constrictions can be added to study the impact of ventricular folds, tongue, or lips.

\section{CURRENT S ING ING-VOICE RESEARGH PROJECTS}

Selected studies conducted on the singing voice at the Speech and Cognition Department of GIPSAlab will now be briefly described. All these studies result from national and/or international collaborations. The main partners are:
- at a national level: Lutherie Acoustique Musique (LAM) Team (IJLRA, Paris), Audio Acoustique (AA) Team (LIMSI, Orsay), Phonetics and Phonology Laboratory and European Hospital Georges Pompidou (Paris), Speech and Language Laboratory (Aix-en-Provence), University-Hospital La Timone (Marseille).

- at an international level: University-Hospital Hamburg-Eppendorf (Germany), Music Acoustics Group (School of Physics, UNSW, Sydney, Australia).

\section{Singing-voice registers and identification of laryngeal mechanisms}

One to several registers may be used in singing (Henrich, 2006). Singing-voice registers are defined by their perceived homogeneity of timbre. They are characterised by specific adjustments of the breathing, phonatory and articulatory systems. They may also be exclusively defined on a laryngeal level. They are then synonymous with laryngeal mechanisms, and they correspond to specific biomechanical and functional adjustments. In speaking and singing, the human voice makes use of four laryngeal mechanisms (Mo, M1, M2, M3 - see Henrich, 2006; Roubeau, Henrich, \& Castellengo, 2009). Much has still to be discovered on the Mo and $\mathrm{M}_{3}$ mechanisms, which are used to produce the lowest and highest tones among the human vocal pitch range. Laryngeal mechanisms M1 (the "chest" or "modal" laryngeal register) and M2 ("falsetto" (for men) or "head" (for women) laryngeal register) are better understood. They correspond to a coupling ( $\left.\mathrm{M}_{1}\right)$ or decoupling (M2) between the superficial and deep layers of the vocal folds. Electroglottography, which is used to measure glottal contact, is helpful for identification the laryngeal-mechanism of a given voice production (Henrich, d'Alessandro, Castellengo, \& Doval, 2004). The EGG-signal amplitude is often much weaker in $\mathrm{M}_{2}$ than in $\mathrm{M}_{1}$, and the correlates between glottal parameters such as the contact, open or closed quotients, and pitch and voice intensity are dependent on the laryngeal mechanism (Henrich, d'Alessandro, Castellengo, \& Doval, 2005). 


\section{Resonance strategies in western classical singing and in Bulgarian women singing}

Direct measurement of vocal-tract resonance frequencies during singing allows both the study of the resonance strategies of singers and relating them to the glottal vibratory behavior measured by electroglottography. The first-resonance frequency $(R 1)$ is nearly always higher or close to the first voice harmonic $\left(f_{\mathrm{O}}\right)$ to improve the energy transfer between the acoustical glottal source and the radiated space. Above pitch $\mathrm{D}_{5}$ (Joliveau, Smith, $\&$ Wolfe, 2004), soprano singers tune the first resonance frequency to the first harmonic $\left(R 1: f_{\mathrm{O}}\right)$. They usually keep this tuning as high in pitch as they can, by acting on their articulators (such as mouth opening, jaw lowering). In the top part of their vocal range, they may make use of other strategies, such as a $R 2: f_{\mathrm{O}}$ tuning (Garnier, Henrich, Smith and Wolfe, 2010). As long as the sung pitch remains below the first-resonance frequency, male and female singers do not show a single systematic resonance-tuning strategy (Henrich, Smith, \& Wolfe, 2011). Their various strategies depend on the sung vowel and on the desired timbre. As an example, Bulgarian female singers make use of a systematic $R 1: 2 f_{\mathrm{O}}$ tuning between the first resonance frequency and the second harmonic, so as to boost the spectral energy of this harmonic and to produce a timbre characteristic of this style of singing (Henrich, Kiek, Smith, \& Wolfe, 2007).

\section{Use of ventricular folds in singing}

The ventricular folds, also called "false vocal folds", are located above and in the vincinity of the vocal folds. They may be used as an additional laryngeal vibrator (Bailly, Henrich, \& Pelorson, 2010), in the case of very low-pitch voices such as Tibetan Monks, Mongolian throat singing, Sardinian Bassu singing, and Human Beatbox. The impact of a ventricular constriction on the vocal-folds vibratory movements has been studied from a theoretical point of view on replicas and from a physiological point of view in human speakers and singers (Bailly et al., 2010;
Bailly, Pelorson, Henrich, \& Ruty, 2008). When the ventricular folds move apart, they may contribute to reinforce glottal vibratory movement. When they are too close to each other (narrow ventricular constriction), they may disturb the vibration. The ventricular folds may vibrate in a sustained way in interaction with the glottal vibratory movement and with or without consequences on the perceived pitch.

\section{Singing voice as a tool to improve phonetical learning of French as a foreign language}

Music has a favorable impact on learning processes. In language learning, the use of sung sentences facilitates the segmentation of words in a foreign language compared to spoken sentences. Therefore we can question whether exercises in singing could help to improve the phonetical learning of a foreign language. This project is consistent with the AIRS research goal of determining the use of singing in teaching of other skills and knowledge.

We have focused on the learning of French as a foreign language, and we have explored how the use of singing-voice exercices in the teaching classroom would facilitate the acquisition of French phonemes (Cornaz, Henrich, \& Vallée, 2010). A preliminary experiment was conducted on Italianspeaking students learning French. The oral vowels of the Italian standard phonologic system were chosen, as they differ from those of French by the lack of two rounded anterior phonemes $/ y /$ and $/ \varnothing /$. In comparing a common phonetic teaching with a reference method traditionally used for teaching/ learning French as a foreign language to a similar phonetic teaching including additional singingvoice exercises, we observed that the participants who were taught with additional singing-voice exercises learned to produce the anterior phonemes $/ y /$ and $/ \varnothing /$ in the acoustical regions expected for these vowels in French and to reduce markedly the confusion (overlap of scattering regions) between them and with close phonemes (in particular /i/ and $/ \mathrm{u} /)$. 


\section{CONGLUSION}

The Speech and Cognition Department of GIPSAlab is a leading site for singing-voice research in France, linked to several laboratories in France and abroad. It participates in the management of European activities, such as the $\mathrm{COST}^{3} 2103$ "Advanced Voice Function Assessment". It collaborates with the Canadian AIRS $^{4}$ research project. It contributes to singing-voice teaching and diffusion, for instance the first French Summer School on "Sciences and Voice: a multidisciplinary approach to the singing voice" ${ }^{"}$. It participates in the organization of voice events, such as the Pan-European Voice Conference $(\mathrm{PEVOC})^{6}$ in Marseille, September 2011. It welcomes collaborative exchanges with any research team involved in singing-voice research, and it may offer opportunities of short-term or longterm stay for doctoral and post-doctoral students, and for foreigner professors or associate professors ${ }^{7}$. It also welcomes singers and singing-teachers interested in understanding their vocal behaviors.

\footnotetext{
${ }^{1}$ The Centre National de la Recherche Scientifique (National Center for Scientific Research) is a governmentfunded research organization, under the administrative authority of France's Ministry of Research. See http://www. cnrs.fr/index.html for more details.
}

${ }^{2}$ MICAL is in reference to Abbot Mical (1730-1789) and his famous "talking heads"

${ }^{3}$ COST is an intergovernmental framework for European Cooperation in Science and Technology, allowing the coordination of nationally-funded research on a European level. See http://www.cost.esf.org/ for more details.

${ }^{4}$ Advancing Interdisciplinary Research in Singing (AIRS), a Major Collaborative Research Initiative of the Social Sciences and Humanities Research Council of Canada. See www. airsplace.ca for more details.

${ }^{5}$ Ecole d'été francophone "Sciences et Voix : approche pluridisciplinaire de la voix chantée", 2009, http://www.gipsa-lab. inpg.fr/summerschool/voixchantee/

${ }^{6}$ The Ninth Pan European Voice Conference (PEVOC9) will be held on August 31 - September 3, 2011, in Marseille, France. Singing voice is one of the main topics, and an European satellite workshop is organized for singing-voice teachers by the European Voice Teacher Association (EVTA) and the French one (AFPC). See http://www.pevoc9.fr/ for more details.

${ }^{7}$ See for instance Eiffel funding (http://www.egide.asso. $\mathrm{fr} / \mathrm{jahia} / J a h i a / a p p e l s / e i f f e l)$ or the European Research and International Cooperation Office of CNRS (Direction Europe de la Recherche et Coopération Internationale, or DERCI, https://dri-dae.cnrs-dir.fr/?lang=en)

\section{R E F E R E N C E S}

Bailly, L., Henrich, N., \& Pelorson, X. (2010). Vocal fold and ventricular fold vibration in perioddoubling phonation: Physiological description and aerodynamic modeling. Journal of the Acoustical Society of America, 127, 3212-3222.

Bailly, L., Pelorson, X., Henrich, N., \& Ruty, N. (2008). Influence of a constriction in the near field of the vocal folds: Physical modeling and experimental validation. Journal of the Acoustical Society of America, 124, 3296-3308.

Cornaz, S., Henrich, N., \& Vallée, N. (2010). L’apport d'exercices en voix chantée pour la correction phonétique en langue étrangère: le cas du français langue étrangère appliqué à des apprenants italiens d'âge adulte. Les Cahiers de l'APLIUT, 29, 103-121.

Garnier, M., Henrich, N., Smith, J., \& Wolfe, J. (2010). Vocal tract adjustments in the high soprano range. Journal of the Acoustical Society of America, 127, 3771-3780.

Henrich, N. (2006). Mirroring the voice from Garcia to the present day: Some insights into singing voice registers. Logopedics Phoniatrics Vocology, 31, 3-14.

Henrich, N., d'Alessandro, C., Castellengo, M., \& Doval, B. (2004). On the use of the derivative of electroglottographic signals for characterization of nonpathological phonation. Journal of the Acoustical Society of America, 115, 1321-1332.

Henrich, N., d'Alessandro, C., Castellengo, M., \& Doval, B. (2005). Glottal open quotient in singing: Measurements and correlation with laryngeal mechanisms, vocal intensity, and fundamental frequency. Journal of the Acoustical Society of America, 117, 1417-1430.

Henrich, N., Kiek, M., Smith, J., \& Wolfe, J. (2006). Resonance strategies used in Bulgarian women's singing style: a pilot study. Logopedics Phoniatrics Vocology, 32, 171-177.

Henrich, N., Smith, J., \& Wolfe, J. (in press). Vocal tract resonances in singing: Strategies used by sopranos, altos, tenors, and baritones. Journal of the Acoustical Society of America.

Joliveau, E., Smith, J., \& Wolfe, J. (2004). Vocal tract resonances in singing: the soprano voice. Journal of the Acoustical Society of America, 116, 2434-2439.

Roubeau, B., Henrich, N., \& Castellengo, M. (2009). Laryngeal vibratory mechanisms: the notion of vocal register revisited. Journal of Voice, 23, 425-438. 


\section{B I O G R A P H I E S}

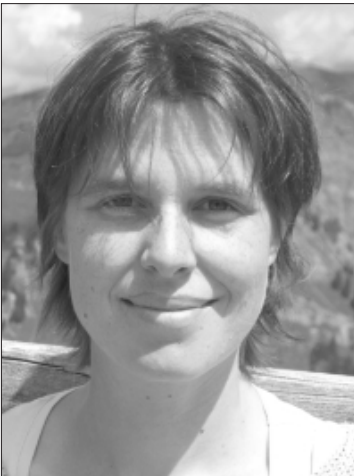

Nathalie Henrich
Nathalie Henrich (born 1974, PhD in Musical Acoustics from the University Paris 6, 2001) is a voice researcher of the French National Centre for Scientific Research (CNRS, Department of Human and Social Sciences). She was educated as a researcher and teacher

in Basic Physics, specializing in human voice production in speech and singing. Her research projects deal with the physical and physiological characterisation of various vocal techniques, such as Western lyrical singing, Sardinian Bassu singing, Bulgarian women's singing, etc. She is also interested in vocal effort and vocal straining in speech and singing. She has worked on the development and improvement of non-invasive experimental techniques for human voice analysis, on perception and verbalisation of voice quality in singing, and on source-filter interaction in singing. Dr. Nathalie Henrich is a member of the French Acoustical Society (SFA), the European Acoustical Society (EAA), the French Phoniatrics and Communication Disorders Society (SFP\&PaCo), the French Ethnomusicology Society (SFE), the French Association of Singing Teachers (AFPC), the COllegium MEdicorum Theatri (COMET). She is Associate Editor for Logopedics Phoniatrics Vocology.
Christophe Savariaux is a CNRS research engineer in charge of the Stendhal experimentation platform. This platform is dedicated to the acquisition of multimodal speech data using different techniques, such as aerodynamic/ physiologic sensors,

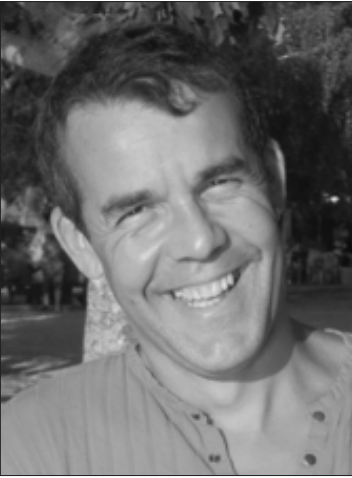

Christophe Savariaux electromagnetic artic-

ulography and multiple cameras. Christophe Savariaux works in collaboration with the teams of the Speech and Cognition Department for which he has developed different software toolkits for data analysis and visualization. His current interest is speech production, in particular the recovery of phonetic contrasts after temporary or permanent impairment of speech articulators.

Received: November 30, 2010 Revision received: December 6, 2010 Accepted: December 6, 2010 